\title{
Hydrotreatment of FCC gasoline catalyzed by CoMo bifunctional catalysts: the effects of acidity on catalytic performance
}

Jingye Chen, Butian Xia, Meng Zheng, Yuhao Zhang, Liyuan Cao, Lixia Dong, Liang Zhao*, Jinsen Gao, Chunming Xu

State Key Laboratory of Heavy Oil Processing, China University of Petroleum (Beijing), Beijing, P.R. China, 102249

State Key Laboratory of Heavy Oil Processing, China University of Petroleum (Beijing), 18 Fuxue Road, Beijing, P.R. China, 102249

*To whom correspondence should be addressed: E-mail: Liang Zhao(liangzhao@cup.edu.cn) 

Table S1. Textural properties of molecular sieves and prepared catalysts.

Table S2. Catalytic performance of AM-10 for model oil and FCC gasoline.

Table S3. Acid sites density and distributions of molecular sieves and oxidized catalysts.

Figure. S1 Mo 3d XPS spectra measured for sulfide catalysts: (a) AM-5, (b) AM-10,

(c) AM-15, (d) AZ-5, (e) AZ-10, (f) AZ-20 and (g) $\mathrm{CoMo} / \gamma-\mathrm{Al}_{2} \mathrm{O}_{3}$.

Figure S2. S 2p XPS spectra measured for sulfide catalysts: (a) AM-5, (b) AM-10, (c) $\mathrm{AM}-15$, (d) AZ-5, (e) AZ-10, (f) AZ-20 and (g) $\mathrm{CoMo} / \gamma-\mathrm{Al}_{2} \mathrm{O}_{3}$.

Figure S3. The mechanism of catalytic performance of bifunctional catalysts. 
Table S1. Textural properties of molecular sieves and prepared catalysts

\begin{tabular}{cccccccc}
\hline Samples & $\begin{array}{c}\mathrm{S}_{\mathrm{BET}^{\mathrm{a}}} \\
\left(\mathrm{m}^{2} \cdot \mathrm{g}^{-1}\right)\end{array}$ & $\begin{array}{c}\mathrm{S}_{\text {ext }}{ }^{\mathrm{b}} \\
\left(\mathrm{m}^{2} \cdot \mathrm{g}^{-1}\right)\end{array}$ & $\begin{array}{c}\mathrm{S}_{\mathrm{mic}^{\mathrm{c}}} \\
\left(\mathrm{m}^{2} \cdot \mathrm{g}^{-1}\right)\end{array}$ & $\begin{array}{c}\mathrm{V}_{\mathrm{t}}{ }^{\mathrm{d}} \\
\left(\mathrm{cm}^{3} \cdot \mathrm{g}^{-1}\right)\end{array}$ & $\begin{array}{c}\mathrm{V}_{\mathrm{mes}}{ }^{\mathrm{e}} \\
\mathrm{cm}^{3} \cdot \mathrm{g}^{-1}\end{array}$ & $\begin{array}{c}\mathrm{V}_{\text {mic }{ }^{\mathrm{f}}} \\
\mathrm{cm}^{3} \cdot \mathrm{g}^{-1}\end{array}$ & $\begin{array}{c}\mathrm{D}_{\text {pore }}{ }^{\mathrm{g}} \\
(\mathrm{nm})\end{array}$ \\
\hline $\mathrm{\gamma}-\mathrm{Al}_{2} \mathrm{O}_{3}$ & 235 & 235 & 0 & 0.60 & 0.60 & 0 & 10.2 \\
$\mathrm{HZSM}-5$ & 338 & 81 & 257 & 0.20 & 0.05 & 0.15 & 2.3 \\
$\mathrm{AZ}-5$ & 199 & 168 & 31 & 0.42 & 0.40 & 0.02 & 8.5 \\
$\mathrm{AZ}-10$ & 215 & 150 & 65 & 0.41 & 0.36 & 0.05 & 7.3 \\
$\mathrm{AZ}-20$ & 224 & 138 & 86 & 0.40 & 0.36 & 0.04 & 5.7 \\
$\mathrm{MCM}-41$ & 719 & 705 & 14 & 0.69 & 0.69 & 0 & 3.9 \\
$\mathrm{AM}-5$ & 201 & 201 & 0 & 0.41 & 0.41 & 0 & 8.1 \\
$\mathrm{AM}-10$ & 232 & 232 & 0 & 0.44 & 0.44 & 0 & 7.6 \\
$\mathrm{AM}-15$ & 256 & 256 & 0 & 0.43 & 0.43 & 0 & 6.6 \\
\hline
\end{tabular}

${ }^{a}$ : the total surface area; ${ }^{b}$ : the external surface area; ${ }^{c}$ : the microspore area;

d: the total pore volume; e: the mesopore volume; f: the microspore volume;

$\mathrm{g}$ : the average pore diameter. 
Table S2. Catalytic performance of AM-10 and commercial HDS catalyst for FCC gasoline

\begin{tabular}{ccc}
\hline & AM-10 & Commercial HDS catalyst \\
\hline HDS $\%$ & 86.3 & 85.4 \\
HYDO $\%$ & 22.6 & 58.3 \\
HDS/HYDO & 7.8 & 2.2 \\
$\triangle$ RON & -1.1 & -3.3 \\
\hline
\end{tabular}

The results of catalytic performance of AM-10 and a commercial HDS catalyst for FCC gasoline are listed in Table S2. It can be seen that the conversion of sulfur compounds (HDS\%) of AM-10 was $86.3 \%$, slightly higher than commercial HDS catalyst $(85.4 \%)$. More importantly, the hydrogenation of olefins (HYDO\%) were obviously different for AM-10 and its commercial counterpart: the HYDO\% of AM-10 was only $22.6 \%$ greatly lower than the commercial HDS catalyst (58.3\%), which led to an excellent selectivity of HDS/HYDO (7.8) for AM-10. This can be explained that more terminal olefins were first isomerized to internal one which are difficult to be saturated mentioned in the manuscript. It is well-known that the olefin is one of the main contributors of octane number in FCC gasoline. Therefore, AM-10 had a supreme protection of octane number (The loss of octane number was only 1.1 unit) during HDS process. In conclusion, AM-10 has a great potential in producing high-quality gasoline. 
Table S3. Acid sites density and distributions of molecular sieves and oxidized catalysts

\begin{tabular}{|c|c|c|c|c|c|c|c|}
\hline \multirow{3}{*}{ Samples } & \multicolumn{7}{|c|}{ Density of acid sites $/ \mu \mathrm{mol} \cdot \mathrm{m}^{-2}$} \\
\hline & \multicolumn{4}{|c|}{$\begin{array}{l}\text { Total acid sites } \\
\qquad\left(200^{\circ} \mathrm{C}\right)\end{array}$} & \multicolumn{3}{|c|}{$\begin{array}{l}\text { Moderate and strong acid sites } \\
\qquad\left(350^{\circ} \mathrm{C}\right)\end{array}$} \\
\hline & $\mathrm{L}$ & $\mathrm{B}$ & $\mathrm{B}+\mathrm{L}$ & $\mathrm{B} / \mathrm{L}$ & $\mathrm{L}$ & $\mathrm{B}$ & $\mathrm{B}+\mathrm{L}$ \\
\hline$\gamma-\mathrm{Al}_{2} \mathrm{O}_{3}$ & 0.54 & 0.00 & 0.54 & - & 0.22 & 0.00 & 0.22 \\
\hline HZSM-5 & 0.12 & 0.82 & 0.94 & 6.76 & 0.10 & 0.52 & 0.62 \\
\hline AZ-5 & 0.35 & 0.08 & 0.43 & 0.23 & 0.09 & 0.02 & 0.11 \\
\hline AZ-10 & 0.33 & 0.15 & 0.49 & 0.46 & 0.09 & 0.07 & 0.16 \\
\hline AZ-20 & 0.34 & 0.26 & 0.60 & 0.75 & 0.11 & 0.17 & 0.28 \\
\hline MCM-41 & 0.08 & 0.04 & 0.12 & 0.48 & 0.07 & 0.00 & 0.07 \\
\hline AM-5 & 0.56 & 0.03 & 0.59 & 0.05 & 0.29 & 0.00 & 0.29 \\
\hline AM-10 & 0.44 & 0.04 & 0.48 & 0.10 & 0.27 & 0.00 & 0.27 \\
\hline AM-15 & 0.34 & 0.07 & 0.41 & 0.21 & 0.24 & 0.00 & 0.24 \\
\hline
\end{tabular}



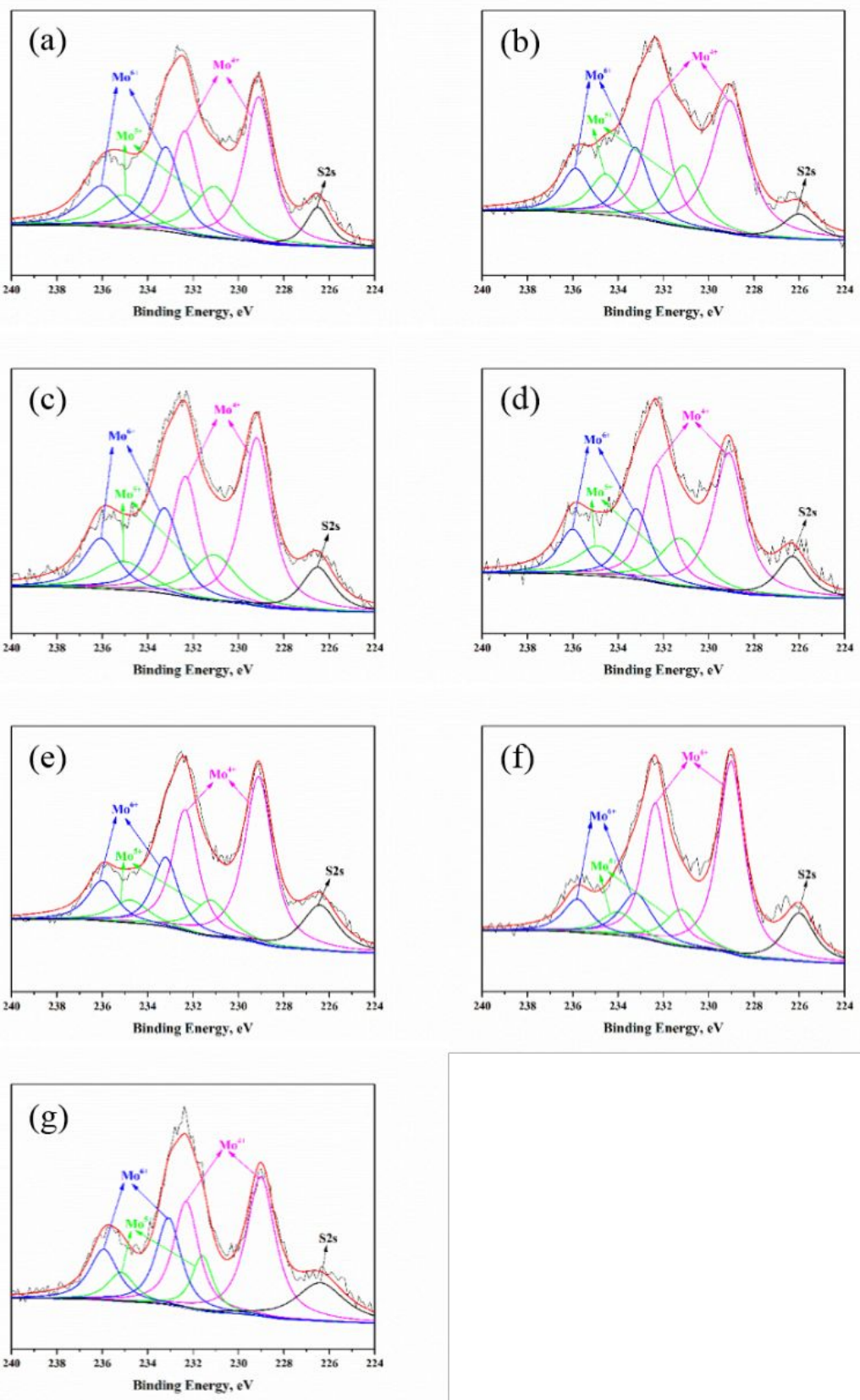

Figure S1. Mo 3d XPS spectra measured for sulfide catalysts: (a) AM-5, (b) AM-10, (c) AM-15, (d) AZ-5, (e) AZ-10, (f) AZ-20 and (g) CoMo/ $\gamma-\mathrm{Al}_{2} \mathrm{O}_{3}$ 

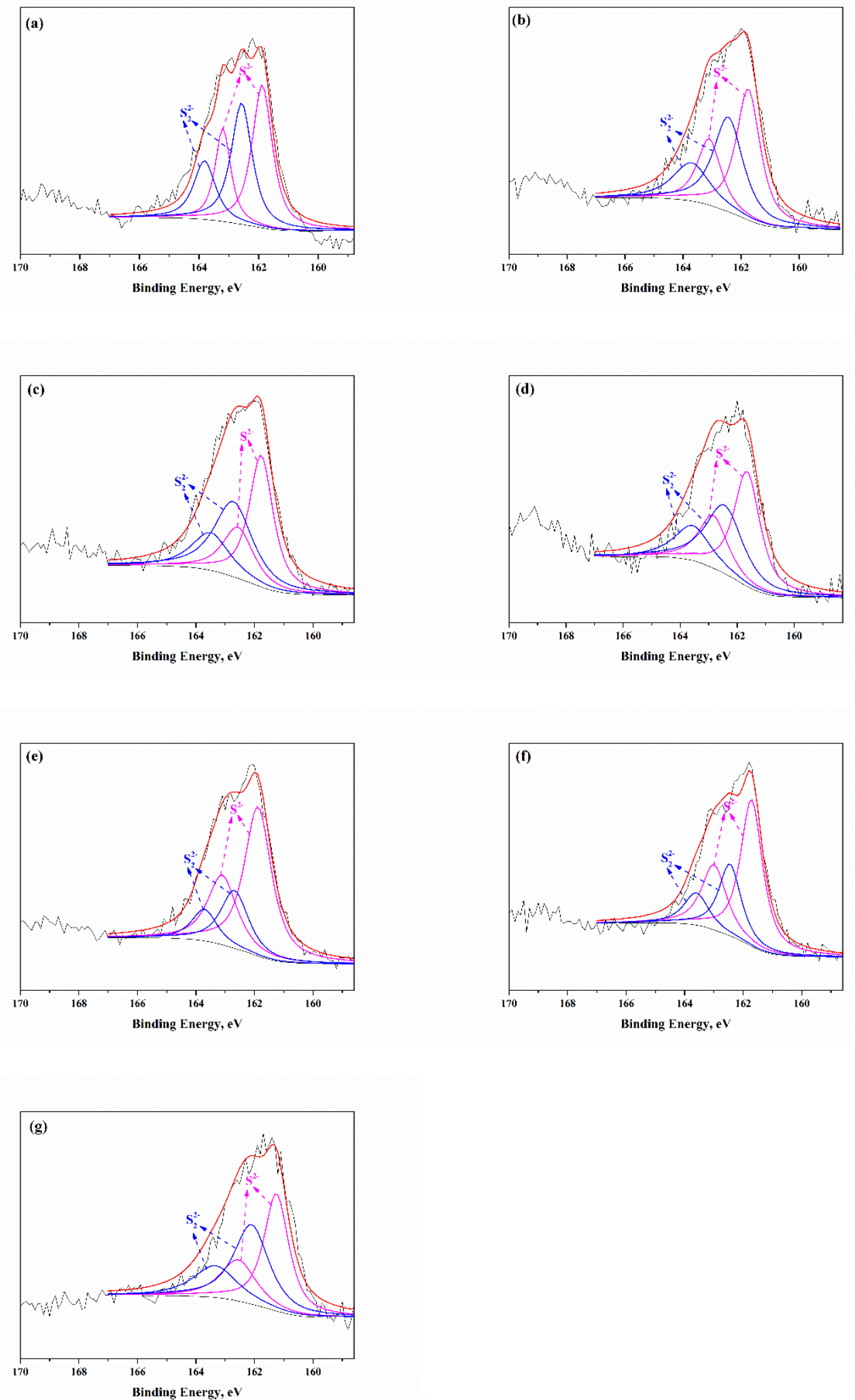

Figure S2. S 2p XPS spectra measured for sulfide catalysts: (a) AM-5, (b) AM-10, (c) AM-15, (d) AZ-5, (e) AZ-10, (f) AZ-20 and (g) CoMo/ $\mathrm{Al}_{2} \mathrm{O}_{3}$ 

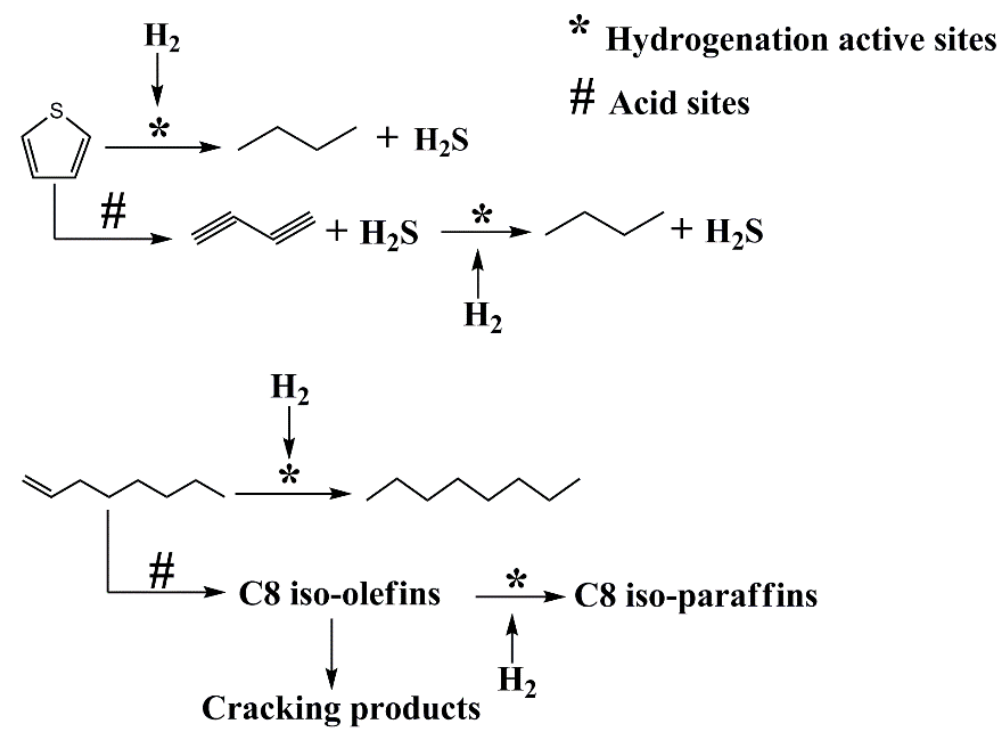

Figure S3. The mechanism of catalytic performance of bifunctional catalysts

Sulfur components are mainly removed over CoMoS species which contain hydrogenation active sites including HDS and HYDO active sites. Additionally, thiophene can also be removed on the acid sites via the cleavage of C-S bonds to generate $\mathrm{H}_{2} \mathrm{~S}$ and butadiene which was hydrogenated to butane. As for olefin conversion, a part of 1-octene is isomerized to branched C8 olefins on BAS considered as the isomerization center. Then, another part of 1-octene and branched C8 olefins are saturated on $\mathrm{MoS}_{2}$ via hydrogenation reaction. Meanwhile, C-C bond cracking occurs on BAS (especially strong BAS) as well, which causes the appearance of small hydrocarbons.

Reference:

1. Welters, W. J. J.; de Beer, V. H. J.; van Santen, R. A., Influence of zeolite acidity on thiophene hydrodesulfurization activity. Applied Catalysis A: General 1994, 119, (2), 253-269. 